
\title{
28 Research Square \\ Exploring the role of eudemonic wellbeing in motivating health behavior: A brief experimental study
}

Abrania Marrero ( $\sim$ amarrerohernandez@g.harvard.edu )

Harvard University T H Chan School of Public Health https://orcid.org/0000-0002-3159-1371

Carrie L. Wyland

Tulane University

Mark J. Wilson

Tulane University School of Public Health and Tropical Medicine

\section{Research Article}

Keywords: wellbeing, health behavior, purpose, values, self-efficacy

Posted Date: February 8th, 2021

DOI: https://doi.org/10.21203/rs.3.rs-173404/v1

License: (c) (i) This work is licensed under a Creative Commons Attribution 4.0 International License.

Read Full License 


\section{Abstract}

Promoting eudemonic psychological wellbeing, including purpose in life and environmental mastery, may motivate positive health behaviors. However, experimental studies exploring cognitive aspects of wellbeing and health behavior are lacking. This study employed a $2 \times 2$ between-subjects factorial design to assess the effects of eliciting a brief saliency in purpose and mastery on anticipated health behavior. A total of 102 participants were randomly assigned to guided visualization tasks on purpose, mastery, both, or a control condition. Dependent measures included a health motivations questionnaire and a food preference task. A principal component factor analysis identified three factors on the questionnaire, and a significant main effect of purpose on the factor 'socially-derived health values' was found. No effects of mastery, nor any effects on the preference task, were detected. While longer-term intervention research is needed, this study provides limited evidence that eliciting a sense of purpose, even briefly, can motivate an increase in the perceived value of health behaviors.

\section{Introduction}

Promoting positive health behaviors such as exercise and a healthy diet can lower the risk of several chronic conditions, including cardiovascular disease, type 2 diabetes, and some cancers (Halpin et al., 2010). Despite these benefits, motivating individuals to engage in health behaviors is challenging. In the United States (US), for example, more than one third (36.6\%) of adults report that they consume fruit less than once per day, and $23.8 \%$ report not having participated in any physical activity in the previous month (CDC, 2018). Leveraging holistic approaches to wellbeing-defined not only as the presence of physical health but also of positive emotions, satisfaction with life, and fulfillment (CDC, 2016)-may play an important role in promoting positive health behavior.

Numerous studies point to a plausible link between psychological factors of wellbeing and chronic disease risk. Biologically, negative psychological states such as anxiety and depression have been shown to increase physiological stress, amplifying cortisol levels and increasing immune-mediated inflammation (Milush et al., 2012; Miller et al., 2006). Reciprocal evidence for the potential role of positive psychological states is also emerging. After adjusting for risk factors such as depression, for example, life satisfaction and positive affect have been associated with a decreased risk for coronary heart disease in healthy populations (Boehm et al., 2011; Davidson et al., 2010). To explain these findings, psychological wellbeing has been proposed to serve as a stimulant for the engagement in behaviors conducive to physical health (Boehm et al., 2012). In a national survey of American adults, for example, high psychological wellbeing was observed among individuals who reported coping with weight stigma via healthy lifestyle behaviors (Himmelstein et al., 2018). Life satisfaction and self-reported happiness have also been associated with higher rates of physical exercise, fruit and vegetable consumption, and less fatty diets in cross-sectional surveys of young adults (Grant et al., 2009; Piqueras et al., 2011).

Although the relationship between psychological health and positive health behavior is likely bidirectional, some longitudinal studies have substantiated temporal precedence for causal claims. For 
example, controlling for demographics, self-rated health, body mass index (BMI), and chronic health conditions, Baruth et al. (2011) found that emotional outlook (i.e. general feelings of happiness and optimism) significantly predicted physical activity after six months among initially inactive men. Nonetheless, very few experimental studies have attempted to corroborate these observational findings, precluding definitive support for a causal effect of psychological wellbeing on health behavior.

Along with limited experimental research, most studies on the promotion of health behavior through wellbeing interventions have thus far focused on the possible effects of hedonic psychological wellbeing -a construct encompassing subjective emotionality and commonly measured by self reports of happiness, life satisfaction, and positive affect (Piqueras et al., 2011). In contrast, evidence for the possible effect of eudemonic dimensions of wellbeing - which center around human drivers of selfactualization including purpose in life, personal growth, self-acceptance, environmental mastery, and autonomy-in motivating health behavior is lacking (Boehm et al., 2012). Eudemonic dimensions of wellbeing are typically long-lasting, more robust to short-term emotions, and have been shown to predict overall wellbeing more strongly than hedonic experiences (McMahan, 2011); thus, promoting these more stable factors of wellbeing may more reliably motivate positive health behaviors. Some researchers have also criticized the current focus on emotionality in promoting physical health, suggesting that these findings can obscure the detrimental risks of pleasure-seeking behavior and diminish the importance of non-hedonic factors (Bloodworth et al., 2007).

Despite a dearth of research, some evidence points to a plausible link between eudemonic wellbeing and health behavior. Purpose in life is a major domain of wellbeing encompassing the extent to which individuals pursue worthwhile goals (George et al., 2016) and, therefore, may have a reasonable potential to influence goals related to lifestyle factors that purposefully improve health and longevity. A longitudinal study examining purpose in life and its association with health values, for example, found that the presence of purpose significantly predicted engagement in healthy eating and physical activity 13 months later (Brassai et al., 2015). Similarly, among older adults in a large, 8-year prospective cohort study, those with the highest reported purpose in life demonstrated a lower risk of becoming inactive and of having an unhealthy BMI (Kim et al., 2020). A high sense of purpose may enable individuals to strive for a longer, more fulfilled life and, therefore, endure the often challenging, time-consuming, and undesirable aspects of health behaviors to attain a worthwhile health goal.

Environmental mastery, a eudemonic component capturing the extent to which individuals perceive life as being under their control and believe in their own capability of achieving a desired outcome, has also been associated with a diminished risk of cardiovascular-related death longitudinally (Surtees et al., 2010). Mastery, related to a sense of autonomy or self-efficacy, is a well-established goal in public health interventions aiming to promote positive health beliefs and, like purpose, may promote physical health in individuals who believe they can engage in health behaviors like diet and exercise that are otherwise difficult to maintain (Mancini, 2021). Although few studies have focused strictly on environmental mastery, autonomy has been associated with less unhealthy snack purchases in a prospective study of adolescents (Stok et al., 2010) and with lower levels of glycated hemoglobin among older adults 
longitudinally (Poole et al., 2019). A recent meta-analysis on health interventions focused on promoting self-determination also found small increases in the engagement of health behaviors such as exercise longitudinally (Ntoumanis et al., 2020). Associations between actual mastery and health behaviors, however, may take years to develop as individuals achieve their desired level of self-regulation and, therefore, may be stronger in older populations (Ali et al., 2018). Less is known about the effect of a brief salience in mastery on shorter-term health motivations.

As cognitive evaluations of wellbeing, experiencing a sense of purpose or mastery may offer more longlasting and well-valued motivations to engage in health behaviors than short-term affect. Salient feelings of purpose support a more proactive health orientation and are inversely associated with health information denial, as individuals recognize risky health behavior can conflict with meaningful aspects of their lives (Steger et al., 2014). A sense of purpose that is aligned with well-established social values, including positive health behaviors, is also expected to result in more feasible and socially-rewarded goalsetting over time (McKnight et al., 2009). Practical implementation of purposeful pursuits will be partly influenced by feelings of mastery (Ryan et al., 2004); for example, individuals reporting a sense of both purpose and mastery experience diminished stress responses to adverse health events and may be better equipped to cope with failure in health behavior maintenance or difficult health decisions (Stoddard et al., 2019). Thus, an interaction between interventions that elicit both constructs might be expected. Finally, although relatively stable and trait-like, short-term interventions promoting positive psychological wellbeing have been carried out and have resulted in substantiated increases in subjective wellbeing both immediately after and at three-to-six-month follow-up in randomized control trials (Bolier et al., 2013), pointing to the feasibility and possible experimental malleability of these constructs.

Informed by these findings, the current study sought to investigate the effects of briefly eliciting the cognitive salience of two indicators of eudemonic wellbeing, purpose and mastery, on anticipated health motivations toward diet and physical activity. Manipulations of purpose and mastery were independently hypothesized to result in higher motivations toward positive health behavior (i.e. diet and exercise) on a self-report measure and elicit healthier decisions in a food preference task compared to those that did not experience the respective manipulation. As a secondary aim, an interaction was also tested, with participants encountering both manipulations predicted to demonstrate the highest scores on both tasks.

\section{Methods}

\section{Design}

The present study utilized a $2 \times 2$ between-subjects factorial design. The first independent variable was purpose in life (purpose writing task or control writing task). The second independent variable was environmental mastery (mastery writing task or control writing task). Health motivations and health behavior, the two assessed dependent variables, were measured through a Likert-scale questionnaire and a forced food choice task, respectively.

\section{Participants and Location}


The study included 102 undergraduate psychology students from Tulane University. Students were included in the study regardless of gender, age, or race, and no demographic information was collected. Subjects were recruited through SONA Systems, an online participant recruitment site, and received partial class credit in their psychology course for their participation. The research occurred in an oncampus psychological laboratory room and took approximately 30 minutes to complete. All participants provided written informed consent. The Institutional Review Board at Tulane University approved this study (1121677).

\section{Materials and Measures}

Guided Visualization Tasks (Eudemonic Wellbeing Manipulations). Purpose and mastery descriptions as well as a script for a guided visualization task were used to conduct eudemonic wellbeing manipulations and a control condition (see Appendix). These guided visualization tasks elicited participants' autobiographical memories to induce a temporary change in their perceived level of purpose, mastery, or both (informed by Fahlman et al., 2009; Battista et al., 1973; Ryff, 1989). Guided visualization and similar writing tasks have been previously implemented in experimental settings and have been shown to induce cognitive salience of psychological wellbeing constructs (Fawn, 2018; Drewery et al., 2018).

Health Motivations Questionnaire. To assess anticipated health behavior, a health motivations questionnaire was assigned to participants, composed of 20 seven-point Likert-scale questions assessing the attitudes, subjective norms, perceived behavioral control, and intentions of subjects regarding diet and physical exercise (see Appendix). These items were adapted from questionnaires (e.g. González et al., 2012; Armitage, 2007) developed using the theory of planned behavior (Ajzen, 1991), among the most widely utilized theoretical models for health behavior prediction and promotion. Evidence for the internal consistency and validity of adapted instruments against, for example, the General Self-Efficacy Scale and Behavioral Regulation in Exercise Questionnaire-2 has been documented (González et al., 2012). The manipulability of the assessed motivations after only short-term behavioral interventions, including those targeting dietary behavior, has also been consistently shown (Hackman et al., 2014). Finally, the ability of health motivations to predict actual health behavior, such as fruit and vegetable consumption, has been confirmed in meta-analyses (Kellar et al., 2005; McDermott et al., 2015).

Forced Food Choice Task. As a more direct measure of health behavior, a novel visual forced food choice task was developed, administered, and composed of 20 two-alternative options, 10 of which contained a healthy and unhealthy alternative and 10 of which were control options to eliminate demand characteristics. A PowerPoint containing the two-alternative questions was displayed on a lab computer, and a hard copy of a response sheet was provided (see Appendix). This forced choice task was adapted from instruments used in discrete choice experiments, which are designed to simulate real-world decisionmaking (e.g.Helfer et al., 2014; Kamphuis et al., 2015) and have demonstrated internal validity and consistency in health-related research (de Bekker-Grob et al., 2012). The two alternatives were chosen with the aim of controlling for all unrelated characteristics (e.g. portion size, taste, appearance) except the perceived healthiness of the food items, including fat and sugar content. For example, one PowerPoint 
slide contained a picture of French fries labeled Choice A next to a picture of mashed potatoes labeled Choice B, with the healthy option being the latter of the two. Control options included, for example, sideby-side visuals of an apple and orange.

\section{Procedure}

After arriving to the lab room, participants first completed the informed consent and then were randomly assigned by the experimenter to one of four conditions, namely 1) purpose writing task only, 2) mastery writing task only, 3) both purpose and mastery writing tasks, and 4) a control condition. A control task was omitted for participants assigned to one eudemonic writing task to avoid loss in the cognitive salience of these constructs.

In the purpose condition, participants were given a description of purpose while the experimenter read the description aloud. Any questions related to the concept were addressed. Next, participants were instructed verbally to recall a memory of a time in their life that was particularly purposeful to them. Participants completed the guided visualization task in which they were prompted by the researcher to recall what they saw, how they felt, what they were thinking, and who they were interacting with during the recalled incident. They were told: 'Take a few minutes to imagine as vividly as possible that you are in this scenario again.' Finally, participants were told: 'Take some time to describe the situation in writing and include as many details as you can.' To ensure privacy and honest responses, the researcher stepped out of the study room while participants completed the writing task, which was allotted approximately seven minutes.

Subjects exposed to the mastery manipulation followed a similar protocol. The experimenter reviewed the description of mastery with participants, addressing any questions. The autobiographical memory recall, guided visualization, and writing tasks were equivalent to those described for the purpose manipulation.

For participants randomly assigned to receive both purpose and mastery manipulations, the time allotted to each guided visualization task was reduced by half (i.e. 3.5 minutes) to maintain a similar time commitment across all four conditions. As a control, when both purpose and mastery manipulations were absent, subjects were asked to participate in the same recall, visualization, and writing tasks regarding the last movie they saw for seven minutes (adapted from Burrow et al., 2016). Although formal manipulation checks were omitted across all conditions to reduce bias in subsequent dependent measures related to demand characteristics, the researcher reviewed the written contents of guided visualization tasks to ensure all participants indeed reflected on their assigned construct.

Dependent measures were administered immediately after the manipulation in all conditions. The forced food choice task was administered before the health motivations questionnaire to limit demand characteristics associated with healthy eating habits. For the forced food choice task, the experimenter turned on the computer screen in front of participants, opened the associated PowerPoint, and provided a response sheet for participants to record their answers. The experimenter instructed participants to click through the twenty questions of the forced food choice task on the screen and record their responses (i.e. 
Choice A or Choice B) on the response sheet. After the completion of this task, the experimenter collected the response sheet and provided a paper copy of the health motivations questionnaire. The instructions on filling out the questionnaire were described. During both measures, the researcher stepped out of the room to ensure privacy. Once all measures were completed, participants were thoroughly debriefed, thanked, and excused.

\section{Results}

\section{Health Motivations Questionnaire}

A principal component factor analysis with varimax rotation was conducted on the 20 -item Health Motivations Questionnaire to identify underlying components of the measure. A three-factor solution emerged, explaining $57 \%$ of the variance (Table 1 ). According to the phrasing of and original rationale for each question (i.e. based on the theory of planned behavior), these identified factors were interpreted as three distinct constructs-namely, 1) socially-derived health values, 2) self-motivated diet intentions, and 3) self-motivated exercise intentions. Items establishing the 'socially-derived health values' construct encompassed ideas involving subjective norms surrounding diet and exercise (e.g. 'people who are important to me think I should engage in a healthy diet/ regular physical activity') as well as highly socially-accepted attitudes toward positive health behavior (e.g. 'a healthy diet/ exercise is beneficial to my overall health'). In contrast, 'self-motivated intentions' toward diet and exercise explored the perceived behavioral control (e.g. 'I believe I have the ability to eat healthily/ exercise'), personal attitudes (e.g. 'regular physical activity/ a healthy diet is pleasant'), and behavioral intentions participants demonstrated (e.g. 'I intend to eat healthily/ exercise over the next two weeks'). Scores for each of these factors were calculated as mean scores out of seven for those items, including items with cross-loadings, for each participant.

Next, a multivariate analysis of variance (MANOVA) was performed to examine the effects of the two independent variables, purpose and mastery, on the three factors. A marginally significant effect of purpose was detected, $F(3,96)=2.323, p=.080$. The corresponding two-way between groups ANOVA indicated a significant main effect of purpose on perceived socially-derived health values, $F(1,98)=$ $5.348, p=.023$ (Table 2). Specifically, subjects in the purpose present condition scored significantly higher on perceived socially-derived health values $(M=6.56)$ than subjects in the purpose absent condition $(M=6.32)$, an effect size of 0.24 points. There was no effect of purpose on either of the other two factors. Additionally, mastery had no significant effect on any of the factors and there were no interaction effects.

\section{Forced Food Choice Task}

A two-way between groups ANOVA was also used to test the effects of purpose and mastery on the scores of the forced food choice task (Table 3$)$. There was no significant main effect of purpose, $F(1$, $98)=0.322, p=.571$ or mastery, $F(1,98)=1.234, p=.269$. There was also no significant interaction between purpose and mastery, $F(1,98)=2.333, p=.130$. 


\section{Discussion}

Current evidence demonstrates a plausible association between eudemonic indicators of psychological wellbeing and health behavior. In the present study, hypotheses regarding whether purpose and mastery would promote engagement in health behaviors were explored, and partial support for a main effect of purpose was found. Participants whose sense of purpose was temporarily made salient via an experimental manipulation scored significantly higher on a measure of perceived 'socially-derived health values' in a Likert-scale health motivations questionnaire. Specifically, subjects contemplating personal experiences in which they felt a high sense of purpose rated the perceived importance, benefits, and subjective norms of diet and exercise higher than comparable controls.

Seminal operationalizations center purpose in life around a fundamental commitment to a set of core values, creating a cognitive framework from which to view meaning, life goals, and fulfillment (Battista et al. 1973). Although the values underlying of an individual's sense of purpose may vary widely (e.g. religiosity, self-expression, community involvement) and shift over time, the ability for these values to motivate the pursuit of meaningful goals is a hallmark of eudemonic wellbeing (George et al., 2016). Related research has correlated purpose with higher-ranked health values and, longitudinally, with engagement in healthy eating and physical activity (Brassai et al., 2015). Results from the present study strengthen this body of research and suggest that a heightened general salience of purpose, even temporarily, can motivate health as a central value and frame positive health behaviors as important and worthwhile goals.

Engagement with a brief writing task on purpose specifically elicited an enhanced salience in perceived socially-derived health values, with participants endorsing motivations related to commonly accepted health values and social norms than those in the control condition. Previous research employing purpose writing tasks confirms that subjects tend to rank social relationships and pro-social activities (e.g. 'hanging out with friends,' 'volunteering') as a primary source of purpose the majority of the time (42-51\%; Ebersole, 1998). Thus, participants in the present study contemplating their life's purpose may have experienced a broadened acceptance towards positive health behavior as a socially-accepted value (Harmon et al., 2016). Contemplating purpose within their social contexts may have led to a temporary conceptualization of health behaviors not only as goals that are worthwhile, but that will be supported and approved by valued peers in their social network.

Contrary to initial predictions, there was no significant effect of purpose on intentions toward diet and exercise and no effect of mastery on any dependent measures. Further, neither purpose nor mastery had a significant effect on responses to the forced food choice task. While a brief salience in purpose led participants to endorse socially-accepted health values, promoting internally motivated aspects of planned behavior-including perceived behavioral control, intentions, and simulated dietary choiceslikely requires more intensive and long-term commitments to improving self-efficacy and self-regulation around health behavior (Ali et al., 2018). More generally, based on relatively high participant responses, a ceiling effect associated with the social desirability of diet and exercise also likely occurred in this 
undergraduate study sample, a population that is highly health conscious and may experience social pressure to pursue positive health behaviors (Harmon et al., 2016). Thus, observed effect sizes were constrained, reducing the experiment's power to detect significant results. Within the general population, however, health motivations and behavior may be more variable and better demonstrate a causal effect of eudemonic wellbeing. Additionally, because purpose increases with age (Morgan et al., 2013), the relevance of these findings in promoting health behavior may be more compelling outside a brief laboratory simulation.

Some limitations in study design should be mentioned. Although writing tasks are a common method to conduct positive psychological interventions (Seligman et al., 2005), no manipulation checks were implemented to control for demand characteristics; thus, the strength of the temporary boost in eudemonic wellbeing, as well as the sustainability of their effects on health behavior, cannot be fully determined. Despite this limitation, an informal review of participants' written responses after task completion did indicate a cognitive salience of these constructs. The forced food choice task, although adapted from validated measures used in discrete choice experiments (e.g. Helfer et al., 2014), was also a novel instrument, so its construct validity could not be determined in this study. Finally, as the effect of eudemonic wellbeing constructs on motivations toward health behavior is likely small (Boehm et al., 2012), increased power, through stronger or longer-lasting manipulations and an increased sample size, is needed to better analyze these relationships, particularly for possible interaction effects. Despite difficulties in translating psychological tasks into a laboratory setting, these experimental manipulations are crucial to establish potential causal claims and support longitudinal interventions promoting eudemonic wellbeing and positive health behavior.

Eudemonic wellbeing has been described as a lifelong pursuit of virtuous goals, personal growth and development, and self-realization (Ryan et al., 2001). Based on the findings of the present study, promoting eudemonic wellbeing-and particularly enhancing feelings of mastery-likely requires a timeframe of months to years to assess a more stable change. The adoption of positive health behavior similarly develops over time. Therefore, although the present findings related to a temporary salience of purpose speak to a causal effect on health motivations, it is imperative to translate these methods to long-term interventions and a longitudinal study framework. Future experimental studies, for example, can utilize autobiographical narrative writing tasks within a longitudinal design (Singer, 2004) and track changes in health behavior months after the intervention. Eliciting stronger feelings of eudemonic wellbeing in a long-term intervention can also involve task-oriented manipulations, in which, for example, the experimenter encourages participants to engage in tasks that personally bring purpose to their lives such as volunteering, attending religious services, and spending more time with family.

Although limited, evidence for the effect of purpose on perceived socially-derived health values was determined in the present study, a compelling indication that physical and psychological health are interrelated and may be concurrently promoted. An emphasis on eudemonic wellbeing can frame engagement in protective health behaviors, which can often feel futile and difficult, as a worthwhile health value. Especially regarding diet and exercise, for which feelings of mastery and self-efficacy may 
be particularly difficult to adopt, it may be beneficial for individuals to contemplate health behaviors as fulfilling positive social norms. Further experimental manipulations, including long-term health interventions, should be developed to better ascertain the causal relationship between positive psychological wellbeing and reduced chronic disease risk. As a construct that embodies fulfillment and the pursuit of worthwhile goals, eudemonic wellbeing has promising effects on health behavior and can be incorporated in public health efforts seeking the holistic promotion of health.

\section{Declarations}

Funding: No funding was received for conducting this study. Conflicts of interest/Competing interests: The authors have no relevant financial or non-financial interests to disclose. Availability of data and material: The datasets generated during and/or analyzed during the current study are available from the corresponding author on reasonable request. Code availability: Code for data analysis is available from the corresponding author on reasonable request. Authors' contributions: Abrania Marrero conceptualized the research question, conducted the experiment, and wrote the manuscript. Mark J. Wilson contributed to the interpretation of the results and the manuscript. Carrie L. Wyland was the principal investigator on the study and contributed to data analysis, interpretation of the results, and the manuscript. All authors listed have reviewed and approved the final version of the manuscript. Ethics approval: The Institutional Review Board at Tulane University approved this study (1121677). Consent to participate: All participants provided written informed consent.

\section{References}

Ali, S., de Araújo Pio, C. S., Chaves, G. S. S., Britto, R., Cribbie, R., \& Grace, S. L. (2018). Psychosocial wellbeing over the two years following cardiac rehabilitation initiation \& association with heart-health behaviors. General Hospital Psychiatry, 52, 48-57. https://doi.org/10.1016/j.genhosppsych.2018.03.006

Ajzen, I. (1991). The theory of planned behavior. Organizational Behavior and Human Decision Processes 50(2), 179-211.

Armitage, C.J. (2007). Effects of an implementation intention-based intervention on fruit consumption. Psychology \& Health 22(8), 917-928.

Baruth, M., Lee, D.C., Sui, X., Church, T.S., Marcus, B.H., Wilcox, S., \& Blair S.N. (2011). Emotional outlook on life predicts increases in physical activity among initially inactive men. Health Education \& Behavior $38,150-158$.

Battista, J. \& Almond, R. (1973). The development of meaning in life. Psychiatry 36(4), 409-427.

Bloodworth, A. \& McNamee, M. (2007). Conceptions of well-being in psychology and exercise psychology research: A philosophical critique. Health Care Analysis 15(2), 107-121. 
Boehm, J.K. \& Kubzansky, L.D. (2012). The heart's content: The association between positive psychological well-being and cardiovascular health. Psychological Bulletin 138(4), 655-691.

Boehm, J.K., Peterson, C., Kivimaki, M. \& Kubzansky, L.D. (2011). Heart health when life is satisfying: Evidence from the Whitehall II cohort study. European Heart Journal32, 2672-2677.

Boiler, L., Haverman, M., Westerhof, G.J., Riper, H., Smit, F., \& Bohlmeijer E. (2013). Positive psychology interventions: A meta-analysis of randomized controlled studies. BMC Public Health 13, 119.

Brassai, L., Piko, B. \& Steger, M. (2015). A reason to stay healthy: The role of meaning in life in relation to physical activity and healthy eating among adolescents. Journal of Health Psychology 20(5), 473-482.

Burrow, A., Hill, P., \& Sumner, R. (2016). Leveling mountains: Purpose attenuates links between perceptions of effort and steepness. Personality \& Social Psychology Bulletin 42(1), 94.

Centers for Disease Control and Prevention. (2016). Well-being concepts. Available at https://www.cdc.gov/hrqol/wellbeing.htm (accessed 6 July 2020).

Centers for Disease Control and Prevention. (2018). Behavioral Risk Factor Surveillance System Survey Data. Atlanta, Georgia: U.S. Department of Health and Human Services, Centers for Disease Control and Prevention. Available at https://www.cdc.gov/brfss/brfssprevalence/ (accessed 6 July 2020).

Davidson, K.W., Mostofsky, E., \& Whang, W. (2010). Don't worry, be happy: Positive affect and reduced 10year incident coronary heart disease: The Canadian Nova Scotia Health Survey. European Heart Journal $31,1065-1070$.

de Bekker-Grob, E. W., Ryan, M., \& Gerard, K. (2012). Discrete choice experiments in health economics: A review of the literature. Health Economics, 21(2), 145-172.

Drewery, D. W., Cormier, L. A., Prettti, T. J., \& Church, D. (2019). Improving Unmatched Co-Op Students' Emotional Wellbeing: Test of Two Brief Interventions. International Journal of Work-Integrated Learning, 20(1), 43-53.

Ebersole, P. (1998). Types and depth of written life meaning. In Wong PTP \& Fry PS (eds), The human quest for meaning. A handbook of psychological research and clinical applications. Mahwah, NJ: Erlbaum, pp. 179-192.

Fahlman, S.A., Mercer, K.B., Gaskovski, P., Eastwood, A.E., \& Eastwood, J.D. (2009). Does a lack of life meaning cause boredom? Results from psychometric, longitudinal, and experimental analyses. Journal of Social and Clinical Psychology 28(3), 307-340.

Fawn, M. (2018). The functions of nostalgia for well-being in older adults. [PhD Thesis]. University of Surrey. 
George, L.S. \& Park, C.L. (2016). Meaning in life as comprehension, purpose, and mattering: Toward integration and new research questions. Review of General Psychology 20, 205-220.

González, S. T., López, M. C. N., Marcos, Y. Q., \& Rodríguez-Marín, J. (2012). Development and validation of the theory of planned behavior questionnaire in physical activity. The Spanish Journal of Psychology, 15(2), 801.

Grant, N., Wardle, J., \& Steptoe A. (2009). The relationship between life satisfaction and health behavior: A cross-cultural analysis of young adults. International Journal of Behavioral Medicine 16(3), 259-68.

Hackman, C. L., \& Knowlden, A. P. (2014). Theory of reasoned action and theory of planned behaviorbased dietary interventions in adolescents and young adults: A systematic review. Adolescent Health, Medicine and Therapeutics, 5, 101-114. https://doi.org/10.2147/AHMT.S56207

Halpin, H. A., Morales-Suárez-Varela, M. M., \& Martin-Moreno, J. M. (2010). Chronic disease prevention and the new public health. Public Health Reviews, 32(1), 120-154.

Harmon, B.E., Forthofer, M., Bantum, E.O., \& Nigg, C.R. (2016). Perceived influence and college students' diet and physical activity behaviors: An examination of ego-centric social networks. BMC Public Health, 16(1), 1-10.

Helfer, P. \& Shultz, T. (2014). The effects of nutrition labeling on consumer food choice: A psychological experiment and computational model. Annals of the New York Academy of Sciences, 13311(1), 174-185.

Himmelstein, M.S., Puhl, R.M., \& Quinn, D.M. (2018). Weight stigma and health: The mediating role of coping responses. Health Psychology, 37(2), 139-147.

Kamphuis, C. B., de Bekker-Grob, E. W., \& van Lenthe, F. J. (2015). Factors affecting food choices of older adults from high and low socioeconomic groups: A discrete choice experiment. The American Journal of Clinical Nutrition, 101(4), 768-774. https://doi.org/10.3945/ajcn.114.096776

Kellar, I. \& Abraham, C. (2005). Randomized controlled trial of a brief research-based intervention promoting fruit and vegetable consumption. British Journal of Health Psychology, 10(4), 543-558.

Kim, E.S., Shiba, K., Boehm, J.K., \& Kubzansky, L.D. (2020). Sense of purpose in life and five health behaviors in older adults. Preventive Medicine, 139, 106172.

Lyubomirsky, S., King, L., \& Diener, E. (2005). The benefits of frequent positive affect: Does happiness lead to success? Psychological Bulletin, 131(6), 803-855.

Mancini, M. A. (2021). Models of Change and Well-Being from Behavioral Health Disorders. In M. A. Mancini (Ed.), Integrated Behavioral Health Practice (pp. 59-84). Springer International Publishing. https://doi.org/10.1007/978-3-030-59659-0_3 
McDermott, M., Oliver, M., Svenson, A., Simnadis, T., Beck, E., Coltman, T. . . Sharma, R. (2015). The theory of planned behaviour and discrete food choices: A systematic review and metaanalysis. International Journal of Behavioral Nutrition and Physical Activity, 12, 162.

McKnight, P. E., \& Kashdan, T. B. (2009). Purpose in Life as a System that Creates and Sustains Health and Well-Being: An Integrative, Testable Theory. Review of General Psychology, 13(3), 242-251. https://doi.org/10.1037/a0017152

McMahan, E.A. \& Estes, D. (2011). Hedonic versus eudaimonic conceptions of well-being: Evidence of differential associations with self-reported well-being. Social Indicators Research, 103(1).

Miller, G. \& Blackwell, E. (2006). Turning up the heat: Inflammation as a mechanism linking chronic stress, depression, and heart disease. Current Directions in Psychological Science 15(6), 269-272.

Milush J., York, V., Prather, A., Nixon, D., Frederick, H., \& Epel, E. (2012). Effect of chronic stress and in vivo cortisol measures on immune cell glucocorticoid receptor expression and cellular immune activation. European Journal of Psychotraumatology, 3: 1.

Morgan, J. \& Robinson, O. (2013). Intrinsic aspirations and personal meaning across adulthood: Conceptual interrelations and age/sex differences. Developmental Psychology, 49(5), 999-1010.

Ntoumanis, N., Ng, J.Y.Y., Prestwich, A., Quested, E., Hancox, J.E., Thøgersen-Ntoumani, C., Deci, E.L., Ryan, R.M., Lonsdale, C., \& Williams, G.C. (2020). A meta-analysis of self-determination theory-informed intervention studies in the health domain: Effects on motivation, health behavior, physical, and psychological health. Health Psychology Review, 0(0), 1-31.

Piqueras, J.A., Kuhne, W., Vera-Villarroel, P., Van Straten, A., \& Cuijpers, P. (2011). Happiness and health behaviours in Chilean college students: A cross-sectional survey. BMC Public Health 11, 443-443.

Poole, L., Hackett, R. A., Panagi, L., \& Steptoe, A. (2020). Subjective wellbeing as a determinant of glycated hemoglobin in older adults: Longitudinal findings from the English Longitudinal Study of Ageing. Psychological Medicine, 50(11), 1820-1828. https://doi.org/10.1017/S0033291719001879

Ryan, R.M. \& Deci, E.L. (2001). On happiness and human potentials: A review of research on hedonic and eudaimonic well-being. Annual Review of Psychology, 52(1), 141-166.

Ryan, R.M. \& Deci, E.L. (2004). Avoiding death or engaging life as accounts of meaning and culture: Comment on Pyszczynski et al. (2004). Psychological Bulletin, 130, 473-477.

Ryff, C. \& Sarason, I.G. (1989). Happiness is everything, or is it? Explorations on the meaning of psychological well-being. Journal of Personality and Social Psychology, 57(6), 1069-1081.

Seligman, M.E.P., Steen, T.A., Park, N., \& Peterson, C. (2005). Positive psychology progress: Empirical validation of interventions. American Psychologist, 60(5), 410-421. 
Singer, J. (2004). Narrative identity and meaning making across the adult lifespan: An introduction. Journal of Personality, 72(3), 437-460.

Steger, M. F., Fitch-Martin, A. R., Donnelly, J., \& Rickard, K. M. (2015). Meaning in life and health: Proactive health orientation links meaning in life to health variables among American undergraduates. Journal of Happiness Studies, 16(3), 583-597.

Steptoe, A., O'Donnell, K., Marmot, M., \& Wardle, J. (2008). Positive affect, psychological well-being, and good sleep. Journal of Psychosomatic Research, 64, 409-415.

Stoddard, S. A., Pierce, J., Hurd, N. M., Bauermeister, J. A., \& Zimmerman, M. A. (2019). Purpose and mastery as predictors of perceived health and substance use problems. Journal of Community Psychology, 47(6), 1514-1529. https://doi.org/10.1002/jcop.22200

Stok, F.M., De Ridder, D.T., Adriaanse, M.A., \& De Wit, J.B. (2010). Looking cool or attaining self-rule. Different motives for autonomy and their effects on unhealthy snack purchase. Appetite, 54, 607-610.

Surtees, P.G., Wainwright, N.W.J., Luben, R., Wareham, N.J., Bingham, S.A., \& Khaw, K.T. (2010). Mastery is associated with cardiovascular disease mortality in men and women at apparently low risk. Health Psychology, 29, 412-420.

\section{Tables}

Table 1

Factor Loadings for Principal Component Factor Analysis with Varimax Rotation of Health Motivations Questionnaire 


\begin{tabular}{|c|c|c|c|}
\hline & $\begin{array}{l}\text { Socially- } \\
\text { Derived } \\
\text { Health } \\
\text { Values }\end{array}$ & $\begin{array}{l}\text { Self- } \\
\text { Motivated } \\
\text { Diet } \\
\text { Intentions }\end{array}$ & $\begin{array}{l}\text { Self-Motivated } \\
\text { Exercise } \\
\text { Intentions }\end{array}$ \\
\hline $\begin{array}{l}\text { How pleasant do you think regular physical activity } \\
\text { would be? }\end{array}$ & & & .662 \\
\hline $\begin{array}{l}\text { If it were entirely up to me, I am confident that I } \\
\text { would be able to participate in regular physical } \\
\text { activity. }\end{array}$ & & & .724 \\
\hline $\begin{array}{l}\text { How beneficial do you think regular physical } \\
\text { activity would be to your overall health? }\end{array}$ & .476 & & \\
\hline $\begin{array}{l}\text { I will try to engage in regular physical activity over } \\
\text { the next two weeks. }\end{array}$ & & & .847 \\
\hline $\begin{array}{l}\text { People who are important to me think I should } \\
\text { engage in regular physical activity. }\end{array}$ & .675 & & \\
\hline $\begin{array}{l}\text { I intend to participate in regular physical activity } \\
\text { over the next two weeks. }\end{array}$ & & & .830 \\
\hline $\begin{array}{l}\text { People who are important to me would approve of } \\
\text { my participating in regular physical activity. }\end{array}$ & .610 & & \\
\hline $\begin{array}{l}\text { I believe I have the ability to participate in regular } \\
\text { physical activity. }\end{array}$ & & & .622 \\
\hline $\begin{array}{l}\text { Over the next two weeks, I intend to exercise at least } \\
\text { times per week. }\end{array}$ & & & .722 \\
\hline $\begin{array}{l}\text { How important do you think regular physical } \\
\text { activity would be? }\end{array}$ & .584 & & \\
\hline $\begin{array}{l}\text { How important do you think a healthy diet would } \\
\text { be? }\end{array}$ & .507 & .533 & \\
\hline $\begin{array}{l}\text { I will try to maintain a healthy diet over the next two } \\
\text { weeks. }\end{array}$ & & .837 & \\
\hline $\begin{array}{l}\text { If it were entirely up to me, I am confident that I } \\
\text { would be able to eat healthily. }\end{array}$ & & .756 & \\
\hline $\begin{array}{l}\text { People who are important to me would approve of } \\
\text { my eating healthily. }\end{array}$ & .760 & & \\
\hline How pleasant do you think a healthy diet would be? & & .639 & \\
\hline $\begin{array}{l}\text { People who are important to me think I should eat } \\
\text { healthily. }\end{array}$ & .751 & & \\
\hline $\begin{array}{l}\text { I intend to maintain healthy eating habits over the } \\
\text { next two weeks. }\end{array}$ & & .826 & \\
\hline I believe I have the ability to eat healthily. & & .684 & \\
\hline
\end{tabular}


Next time you choose a meal or snack, how likely is

it that you will consider its health benefits or

disadvantages?

How beneficial do you think a healthy diet would be $\quad .466$ to your overall health?

Note. Factor loadings $<.4$ are suppressed.

Table 2

Health Motivations Questionnaire Separate ANOVA Results and Descriptive Statistics 


\begin{tabular}{|c|c|c|c|c|c|}
\hline & $N$ & $M$ & $S D$ & $F$ & $p$ \\
\hline \multicolumn{6}{|l|}{ Purpose in Life } \\
\hline Self-Motivated Diet Intention & & & & 1.850 & .177 \\
\hline Present & 52 & 5.54 & 1.109 & & \\
\hline Absent & 50 & 5.24 & 1.112 & & \\
\hline Self-Motivated Exercise Intention & & & & 0.003 & .957 \\
\hline Present & 52 & 5.69 & 1.070 & & \\
\hline Absent & 50 & 5.70 & 0.929 & & \\
\hline Socially-Derived Health Values & & & & 5.348 & $.023^{\star}$ \\
\hline Present & 52 & 6.56 & 0.465 & & \\
\hline Absent & 50 & 6.32 & 0.581 & & \\
\hline \multicolumn{6}{|l|}{ Environmental Mastery } \\
\hline Self-Motivated Diet Intention & & & & 0.162 & .688 \\
\hline Present & 51 & 5.43 & 1.091 & & \\
\hline Absent & 51 & 5.35 & 1.148 & & \\
\hline Self-Motivated Exercise Intention & & & & .166 & .684 \\
\hline Present & 51 & 5.73 & 0.973 & & \\
\hline Absent & 51 & 5.65 & 1.032 & & \\
\hline Socially-Derived Health Values & & & & 2.696 & .104 \\
\hline Present & 51 & 6.52 & 0.490 & & \\
\hline Absent & 51 & 6.36 & 0.571 & & \\
\hline \multicolumn{6}{|c|}{ Purpose in Life*Environmental Mastery } \\
\hline Self-Motivated Diet Intention & & & & 0.047 & .829 \\
\hline Present/Present & 25 & 5.61 & 1.076 & & \\
\hline Present/Absent & 27 & 5.46 & 1.155 & & \\
\hline Absent/Present & 26 & 5.26 & 1.099 & & \\
\hline Absent/Absent & 24 & 5.22 & 1.150 & & \\
\hline Self-Motivated Exercise Intention & & & & 0.836 & .363 \\
\hline Present/Present & 25 & 5.63 & 0.978 & & \\
\hline
\end{tabular}




\begin{tabular}{|lrrrr|r|}
\hline Present/Absent & 27 & 5.73 & 1.166 & & \\
Absent/Present & 26 & 5.83 & 0.978 & & \\
\hline Absent/Absent & 24 & 5.56 & 0.873 & & \\
\hline Socially-Derived Health Values & & & & 0.287 & .593 \\
\hline Present/Present & 25 & 6.67 & 0.338 & \\
\hline Present/Absent & 27 & 6.44 & 0.542 & \\
Absent/Present & 26 & 6.38 & 0.571 & \\
\hline Absent/Absent & 24 & 6.26 & 0.598 & \\
\hline Note. Scores for healthy food choices out of ten. *Significant at the $p<.05$ level. \\
\hline
\end{tabular}

\begin{tabular}{|lcccccc|}
\hline $\begin{array}{l}\text { Table } 3 \\
\text { Forced Food Choice ANOVA Results }\end{array}$ & & & & & \\
& $N$ & $M$ & $S D$ & $F$ & $p$ \\
\hline Purpose in Life & & & & 0.322 & .571 \\
\hline Present & 52 & 6.33 & 1.581 & & \\
\hline Absent & 50 & 6.12 & 1.848 & & \\
\hline Environmental Mastery & & & & 1.234 & .269 \\
\hline Present & 51 & 6.04 & 1.811 & & \\
\hline Absent & 51 & 6.41 & 1.602 & & \\
\hline Purpose*Environmental Mastery & & & & 2.333 & .130 \\
\hline Present/Present & 25 & 6.40 & 1.500 & & \\
\hline Present/Absent & 27 & 6.26 & 1.678 & & \\
\hline Absent/Present & 26 & 5.69 & 2.035 & & \\
\hline Absent/Absent & 24 & 6.58 & 1.530 & & \\
\hline Note. Scores for healthy food choices out of ten. Significant at the $p<.05$ level. &
\end{tabular}




\section{Supplementary Files}

This is a list of supplementary files associated with this preprint. Click to download.

- Appendix.pdf 